\title{
AUDITORIA DE SISTEMA DE GESTÃO AMBIENTAL: APLICAÇÃO EM UMA INDÚSTRIA ALIMENTÍCIA EM NATAL/RN
}

\author{
Daniel Carvalho Soares \\ Bacharel em Administração de Empresas pela Universidade Federal do Rio Grande do Norte - UFRN \\ dcsoares@yahoo.com.br.
}

\author{
Handson Claudio Dias Pimenta \\ Mestre em Engenharia de Produção pela Universidade Federal do Rio Grande do Norte - UFRN \\ Professor do Instituto Federal de Educação, Ciência e Tecnologia do Rio Grande do Norte - \\ Departamento Acadêmico de Recursos Naturais. \\ handson.pimenta@ifrn.edu.br.
}

\begin{abstract}
RESUMO
A conscientização ambiental vem crescendo globalmente; em consequencia as cobranças sociais aumentam sobre o meio empresarial a fim de que as organizações busquem um desempenho ambiental satisfatório, minimizando a sua potencialidade poluidora. O presente artigo tem como objetivo implementar um modelo de auditoria ambiental estruturado nas especificações e recomendações da ISO 19011 e ISO 14001, visando melhorias no Sistema de Gestão Ambiental de uma empresa do ramo alimentício, localizada na microrregião de Natal/RN. A realização de ações para promoção da melhoria contínua no desempenho ambiental e no processo de adequação ambiental organizacional favorece a sustentabilidade empresarial. Assim, a pesquisa foi classificada como exploratória e descritiva, tendo sido o modelo proposto dividido em três fases: planejamento da auditoria, aplicação do modelo e conclusão da auditoria. Foram consideradas como escopo do modelo a Política Ambiental e a fase de Planejamento do Sistema de Gestão Ambiental. Os resultados apontam que a necessidade da empresa voltar maior atenção para avaliação dos aspectos e impactos ambientais, pois, apesar de existir um procedimento de avaliação, não foram evidenciados registros contendo os aspectos e impactos significativos. Sendo assim, não há confiabilidade no levantamento dos requisitos legais e outros aplicáveis, bem como no estabelecimento dos objetivos, metas e programas. Contudo, a aplicação do modelo permitiu uma análise prática e crítica da situação real da empresa, possibilitando o levantamento de pontos fortes e oportunidades de melhoria na gestão.
\end{abstract}

Palavras-chave: Sistema de Gestão Ambiental; Auditoria Ambiental. Indústria de Alimentos; Desempenho ambiental.

\section{AUDITORSHIP ENVIRONMENTAL MANAGEMENT SYSTEM: A CASE STUDY INTO FOOD COMPANY FROM NATAL-RN}

\begin{abstract}
Environmental awareness has grown globally; in addition, the social pressure on businesses has increased so that organizations may demonstrate a satisfactory environmental performance, while minimizing its potential pollution. This paper aims to implement an environmental audit model structured on specifications and recommendations of ISO 19011 and ISO 14001 in order to improve the Environmental Management System of a food company, located in the micro-region of Natal-RN. The research utilized was exploratory and descriptive, with the model proposed in three phases: audit planning, application of the model and audit conclusions. The results concluded that it is necessary that the company gets a greater focus on environmental aspects and impacts evaluation. Although there is an assessment procedure, there was no evidence of the records containing the aspects and impacts evaluation. Thus, there is no reliability in the legal requirements and other restrictions survey, as well as the establishment of objectives, goals and programs. However, the application of the model allowed a practical and critical analysis of the actual situation of the company, thus enabling the assessment of strengths and opportunities for improvement in management.
\end{abstract}

Keywords: Environmental Management System; Environmental Audit; Food Company; Environmental Performance. 


\section{INTRODUÇÃO}

A conscientização ambiental vem crescendo globalmente, em razão dos efeitos que a poluição têm provocado e que resultam em graves problemas ambientais por todo o mundo. Essa realidade tem gerado diferentes tipos de cobranças sobre o meio empresarial, seja pelo próprio governo, seja pela própria sociedade civil organizada, além de outros, afim de que as organizações busquem um desempenho ambiental satisfatório, minimizando sua potencialidade poluidora.

Assim, vários segmentos da atividade econômica passaram a direcionar parcelas de investimentos e esforços administrativos e operacionais com o objetivo de atingir e demonstrar um desempenho ambiental compatível, controlando seus impactos e levando em consideração sua política e seus objetivos ambientais. Vale destacar que conciliar as características ambientais dos produtos e serviços com os paradigmas da conservação ambiental é, cada vez mais, um requisito essencial para as organizações serem competitivas e manterem posições comerciais, arduamente conquistadas.

Nesse sentido, a implantação de planos e ações na área ambiental, conduzidos por um Sistema de Gestão Ambiental (SGA) e integrados ao conjunto das atividades de gestão, determina a busca por melhoria nas condições ambientais da organização, auxiliando-a a se adequar às normas de gerenciamento ambiental e a aumentar sua competitividade.

O Sistema de Gestão Ambiental consiste em um conjunto de atividades administrativas e operacionais inter-relacionadas para abordar os problemas ambientais atuais ou para evitar o seu surgimento dentro das organizações, podendo ser adotado por qualquer organização que deseje implementar e desenvolver uma política ambiental e gerenciar os seus aspectos ambientais (Barbieri, 2004).

A estruturação de um SGA é estabelecida pela norma internacional de gestão ambiental ISO 14001:2004 que estabelece requisitos para implementar a política, os objetivos e as metas ambientais, além de programas para alcance dos objetivos, monitoração e medição das ações, análise crítica e revisão do SGA. É uma norma aplicável a todos os tipos de organizações e a única da série 14000 a conter requisitos que podem ser objetivamente auditados para fins de certificação ou autodeclaração.

A auditoria ambiental em um SGA surge como um instrumento de verificação das conformidades dos requisitos da ISO 14001, servindo como uma etapa importante na identificação das oportunidades de melhorias e adequações ambientais nas organizações, além de avaliar a contínua melhoria do seu desempenho ambiental e o contínuo atendimento de requisitos legais e da política ambiental.

Partindo desse contexto, esse artigo tem como objetivo analisar a implementação de um modelo de auditoria ambiental estruturado nas especificações e recomendações da ISO 19011 e ISO 14001, visando melhorias no Sistema de Gestão Ambiental de uma empresa do ramo alimentício. Como objetivos específicos, propôs-se, por meio desse trabalho, apresentar auditoria realizada na Política Ambiental, por meio dos requisitos do item 4.2 da ISO 14001, e na fase do planejamento do SGA, por meio dos requisitos do item 4.3 da ISO 14001.

O objeto desse estudo trata-se de uma empresa franquia que atua na fabricação e comercialização de bebidas carbonatadas não alcoólicas, com capacidade média produtiva de 28,58 mil litros por hora, que se localiza na microrregião de Natal, Rio Grande do Norte (RN) e que se destaca por promover o desenvolvimento econômico com geração de emprego e renda para a população local.

Em termos metodológicos, quanto aos seus objetivos, a pesquisa foi classificada como exploratória e descritiva. O modelo proposto foi dividido em três fases: planejamento da auditoria, aplicação do modelo e conclusão da auditoria. O modelo aplicado permitiu uma análise prática e crítica da situação real da empresa, possibilitando o levantamento de pontos fortes e das oportunidades de melhoria na gestão da empresa. 
Para orientar a discussão dessa proposta, esse artigo foi estruturado em seis partes, compostas pela introdução, em que são apresentadas a temática e os objetivos, seguida da revisão de literatura, na qual temas como SGA e auditoria ambiental são fundamentados. Em seguida, na metodologia, o modelo de auditoria é apresentado, tendo nos resultados e discussões, o detalhamento da coleta de informações e a validação do modelo. E, finalmente, são apresentadas as considerações finais e as referências.

\section{REVISÃO DE LITERATURA}

Nesse item são discutidos os temas Sistema de Gestão Ambiental e Auditoria Ambiental que fundamentam a análise e discussão dos resultados.

\subsection{Sistema de Gestão Ambiental}

A padronização dos requisitos de um SGA, frente a importância da série de normas de gerenciamento da qualidade ISO 9000 (ABNT, 2002) e da norma britânica BS 7750 (requisitos de um SGA), a ISO, em 1991, formou o SAGE - Strategic Action Group on the Enviroment, tem o intuito de proceder a investigação acerca da possibilidade de formulação de normas ambientais, que pudessem promover uma abordagem comum à gestão ambiental, aumentar a capacidade da organização de alcançar a medir melhorias no desempenho ambiental, além de facilitar o comércio e remover barreiras. Os estudos do SAGE culminaram na criação do Comitê Técnico - TC 207, incumbido de elaborar normas internacionais que assegurem essa abordagem sistêmica à gestão ambiental e possibilitem a certificação das organizações e dos produtos que a cumpram (Valle, 2000, D'isep, 2004, Moreira, 2006).

Dessa forma, o TC 207 propôs o conjunto de normas da série ISO 14000, que não especificam metas de desempenho ambiental, mas que fornecem às organizações um conjunto de ferramentas para avaliar e controlar o impacto ambiental das suas atividades, produtos ou serviços. Essas normas são direcionadas para seguintes áreas: sistema de gestão ambiental; auditoria ambiental, rotulagem, avaliação do ciclo de vida e declarações ambientais e avaliação de desempenho ambiental (Glavic, Lukman, 2007).

Em termos conceituais, Barbieri (2004) define Sistema de Gestão Ambiental como o conjunto de atividades administrativas e operacionais inter-relacionadas para abordar os problemas ambientais atuais ou para evitar o seu surgimento. A gestão ambiental diferencia-se do conceito do SGA, pois ela atua com atividades isoladas na abordagem dos problemas ambientais enquanto o SGA inter-relaciona as diferentes atividades administrativas e operacionais das organizações.

Por sua vez, a ABNT (2004) define Sistema da Gestão Ambiental como a parte de um sistema de gestão de uma organização utilizada para desenvolver e implementar sua política ambiental e para gerenciar seus aspectos ambientais.

Já para Pimenta et al (2003), um SGA é um conjunto de rotinas e procedimentos sistematizados aplicados por uma organização, visando equilibrar a proteção ambiental e a prevenção da poluição com as necessidades socioeconômicas, atendendo as expectativas das partes interessadas.

Dessa forma, entende-se por SGA o conjunto de atividades que, associadas a um sistema de gestão, possibilita o cumprimento de uma política ambiental por meio da gestão dos aspectos ambientais, visando à obtenção de um desempenho ambiental satisfatório.

A ISO 14001 especifica os requisitos para que um SGA capacite uma organização a desenvolver e implementar sua política e seus objetivos ambientais, levando em consideração requisitos legais e informações sobre aspectos ambientais significativos. Entende-se por requisitos as condições necessárias para alcance de objetivos, assim, um requisito de um SGA determina as ações que condicionam o alcance de objetivos ambientais em uma organização. 
Destaca-se que essa norma é aplicável a todos os tipos e portes de organizações, sendo adequada a diferentes condições geográficas, culturais e sociais. É a única norma da Série 14000 que contém requisitos que podem ser objetivamente auditados para fins de certificação ambiental ou de autodeclaração.

Assim, observa-se que os elementos da norma são baseados na metodologia conhecida como ciclo PDCA - planejar, executar, verificar e agir no inglês - plan, do, check e act. De acordo com a ISO 14001, a estrutura de um SGA obedece a esse ciclo e a abordagem da melhoria contínua, conforme sistematizado na Figura 1.

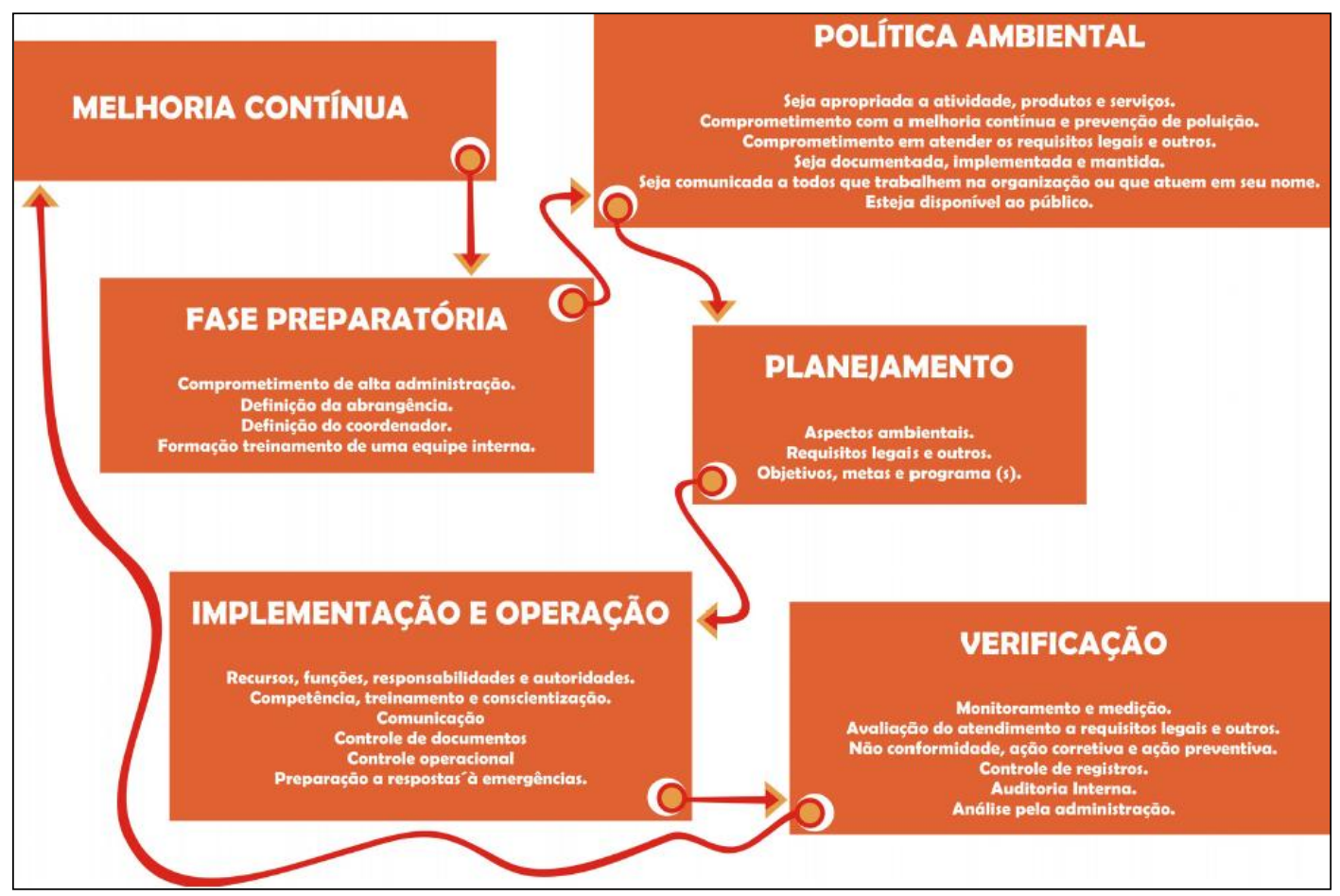

Figura 1 - Estrutura de um Sistema de Gestão Ambiental.

Fonte: Adaptado de (ABNT, 2004).

Seus elementos incluem a criação de uma política ambiental, o estabelecimento de objetivos e metas, a implementação de um programa para alcance dos objetivos, a monitoração e medição de sua eficácia, a correção de problemas e análise e revisão do sistema para aperfeiçoá-lo e melhorar o desempenho ambiental geral (Pereira, Marques, Aguiar, 2003).

\subsection{Auditoria Ambiental}

A palavra auditoria, etimologicamente, vem do latim audire que significa ouvir. Attie (1998) relaciona à origem da palavra auditoria com a finalidade de examinar, corrigir, ajustar e certificar as organizações.

A auditoria ambiental (AA) é conceituada pela ISO 14001:1996 como um processo sistemático e documentado de verificação, executado para obter e avaliar, de forma objetiva, evidências que determinem se o sistema de gestão ambiental de uma organização está em conformidade com os critérios de auditoria do sistema de gestão ambiental estabelecidos pela organização, e para comunicar os resultados desse processo à administração.

Assim, entende-se por auditoria ambiental as atividades de verificação ao atendimento de normas internas, requisitos legais ou outras normas de interesse de uma organização, devendo ser realizadas em períodos pré-estabelecidos ou pela norma a ser auditada. 
Segundo Fornasari Filho et al (1994), a forma mais antiga de auditoria é a contábil, que remonta à antiguidade. A partir de 1950 surgiu a auditoria de qualidade, sendo regulamentada internacionalmente e incluída nas normas técnicas da série ISO 9000.

No fim da década de 1970, a auditoria ambiental surgiu nos Estados Unidos com intuito de fazer um levantamento de conformidade com a legislação. Nessa conjuntura, Barbieri (2004) afirma que esses modelos iniciais procuravam identificar possíveis problemas relacionados com multas, indenizações e outras penalidades ou restrições contidas nas diversas leis federais, estaduais e locais.

No que diz respeito às normas da ISO no campo da auditoria ambiental, em 1996 foram criadas as normas 14010, 14011 e 14012 que estabelecem, respectivamente, os princípios gerais para execução das auditorias, os procedimentos para o seu planejamento e sua execução num Sistema de Gestão Ambiental, e, os critérios para qualificação de auditores. No entanto, em 2002, foi criada a norma ISO 19011 que estabelece diretrizes para auditoria em Sistemas de Gestão da Qualidade e Ambiental, integrando e balizando padrões para auditoria de sistema de qualidade e ambiental.

No Brasil, a auditoria ambiental surgiu, pela primeira vez, por meio da legislação no início da década de 1990, quando da publicação de diplomas legais sobre o tema (SILVA, 2003). No Rio Grande do Norte, a auditoria foi estabelecida pela Lei Complementar $n^{\circ} 272$, de 03/03/2004 que dispõe sobre a Política e o Sistema Estadual do Meio Ambiente, e, é executada pelo Conselho Estadual do Meio Ambiente (CONEMA) junto ao Instituto de Desenvolvimento Econômico e Meio Ambiente do Rio Grande do Norte (IDEMA). A função desses órgãos é estabelecer normas e critérios relativos a auditorias ambientais no estado, entre outras competências.

De forma geral, a auditoria ambiental ainda é incipiente no Brasil e foi implantada de acordo com os padrões estabelecidos na maior parte do mundo. Os primeiros programas de auditoria foram iniciados no fim da década de 1980 e início da década de 1990, normalmente por empresas multinacionais de grande porte (PIVA, 2007).

A auditoria proporciona a identificação de elementos críticos do sistema de gestão da organização, possibilitando que a empresa obtenha subsídios para identificar oportunidades de melhoria que otimizem seu desempenho ambiental.

De acordo com Cajazeira (1998) existem três classes de auditoria que são: auditoria de primeira parte, de segunda parte e de terceira parte. As auditorias de primeira parte ou internas são conduzidas pela própria organização para análise crítica pela direção e outros propósitos internos, e podem formar a base para uma autodeclaração de conformidade da organização (ISO 19011, 2004).

A ISO 19011 (2004) classifica as auditorias de segunda e terceira parte como externas. Segundo ela, as auditorias de segunda parte são realizadas por partes que têm um interesse na organização, tais como clientes, ou por outras pessoas, em seu nome, e, as auditorias de terceira parte são realizadas por organizações externas de auditoria independente, tais como organizações que provêem certificados ou registros de conformidade com os requisitos da ISO 9001 ou ISO 14001.

A auditoria de um sistema de gestão é uma ferramenta que possibilita que seja feita uma avaliação sistemática, documentada, periódica e objetiva sobre como os equipamentos, a gestão e organização ambiental estão desempenhando o objetivo de ajudar a proteger o meio ambiente.

A maioria das auditorias ambientais é a combinação de uma e outra forma de auditoria. Contudo, o objetivo principal de qualquer auditoria ambiental é a realização de um diagnóstico da situação atual para verificar o que está faltando e promover ações futuras que tragam a melhora do desempenho ambiental da empresa.

Os benefícios de uma auditoria ambiental podem ser variáveis se comparados entre organizações distintas, isso se dá mediante a ligação com os objetivos e metas traçados no início da auditoria e o delineamento da política ambiental da organização. 
Sobre o papel da auditoria ambiental na organização, Conceição Neto (2001) explica que é uma ferramenta gerencial, que por meio de uma verificação da performance ambiental, pode auxiliar na determinação de melhorias a serem realizadas.

Cantarino (2009) aponta como benefícios da auditoria ambiental: a conformidade com órgãos ambientais e agências regulamentadoras, responsabilidade coorporativa, avaliação de riscos e responsabilidade civil, financeiro, concorrência e estratégica.

A conformidade com os órgãos ambientais e agências regulamentadora tem como seu principal benefício à proteção contra multas e coerções regulatórias. Por meio das auditorias, não conformidades podem ser identificadas, possibilitando o emprego de ações corretivas para atender as regulamentações e leis ambientais.

A responsabilidade coorporativa trata dos mecanismos de mercado e interesses dos acionistas no desempenho ambiental da empresa para demonstrar por meio da auditoria, o compromisso ambiental, a economia e controle interno dos processos, bem como os benefícios decorrentes disso, como a possibilidade de melhorar a imagem coorporativa, o market share e os lucros.

As auditorias podem ser utilizadas em várias fases da avaliação de riscos ligados a questões ambientais, de segurança e de saúde, que podem acarretar na responsabilidade civil. Aqui se pode aplicar o risco a sistemas de gestão, tecnologia de controle e uso de certos materiais, bem como riscos de processo e produto. Portanto, pode-se usar a auditoria para avaliar e minimizar os riscos. Auditorias mais especializadas e profundas podem ser usadas para investigar a extensão dos problemas em potencial.

Quanto à responsabilidade civil, em termos ambientais, pode-se usar as auditorias ambientais para o entendimento e ação, nos casos de responsabilidade civil em potencial, relacionados a eventos crônicos ou agudos ou ao sistema de gestão. O campo de avaliação de riscos e o papel das auditorias ambientais podem ser aplicados a muitas situações, como o planejamento interno de emergência, a fusão de duas empresas, a realização de parcerias, as renovações ou aquisições de seguros, as aquisições e o planejamento.

Em termos financeiros, a auditoria pode ser uma ferramenta que contribua na tomada de decisões, gerando informações sobre os custos ambientais atuais e as oportunidades de melhorias presentes ou futuras. No âmbito da concorrência e estratégia, a auditoria fornece Informações aos gestores e acionistas que podem ser comparadas com o mercado, possibilitando um melhor detalhamento da situação interna e externa que auxilia na definição das metas estratégicas em alinhamento com a visão e missão da empresa.

\section{MÉTODO DE PESQUISA}

Nesse item é apresentada a classificação e delimitação da pesquisa e descrito o modelo de auditoria utilizado na avaliação e na análise dos dados da empresa estudada.

\subsection{Classificação da Pesquisa}

Segundo Silva e Menezes (2001), a pesquisa pode ser classificada de acordo com quatro critérios: natureza, abordagem do problema, objetivos e procedimentos técnicos. Assim, esse trabalho pode ser classificado, quanto à natureza da pesquisa, como pesquisa aplicada que objetiva gerar conhecimentos práticos dirigidos à solução de problemas específicos.

Tendo como base a abordagem do problema que configura a pesquisa, o design utilizado no desenvolvimento foi de uma pesquisa qualitativa. O estudo qualitativo se justifica, pois se busca diagnosticar a situação da gestão ambiental da empresa do ramo alimentício na microrregião de Natal/RN por meio da aplicação de um modelo de auditoria em relação aos requisitos do item $4.2 \mathrm{e}$ 4.3 da NBR ISO 14001. 
Já referente aos objetivos, essa pesquisa pode ser classificada como exploratória e descritiva. Exploratória porque visa proporcionar maior familiaridade com o problema e construir hipóteses, e descritiva, porque descreve as características de determinada população, envolve o uso de técnicas de coleta de dados, como check list, e observação sistemática, Gil (2001 apud Silva 2001).

Com base nos procedimentos técnicos, a pesquisa é classificada como estudo de caso, que se justifica por envolver o estudo do Sistema de Gestão Ambiental dentro de uma empresa, o que permite o aprofundamento do tema.

\subsection{Delimitação da Pesquisa}

A pesquisa foi realizada em uma indústria de fabricação de bebidas carbonatadas não alcoólicas, localizada na microrregião de Natal, Rio Grande do Norte. A empresa possui 324 funcionários diretos e 55 indiretos e uma capacidade média produtiva de 28,58 mil litros por hora, sendo 6 produtos diferentes em 3 linhas de produção de bebidas - linha de latas, linha de PET (garrafas não retornáveis) e vidro (garrafa retornáveis).

Destaca-se que a empresa possui um Manual de Gestão Integrada que atende ao modelo do Sistema de Gestão Integrada (SGI), que integra os sistemas de gestão da qualidade, meio ambiente e gestão de segurança e saúde do trabalhador e segue o padrão de normas internacionais bem como a norma interna da matriz.

Por outro lado, a empresa não possui nenhuma certificação e está com seu sistema de gestão em processo de implementação. Dessa forma, buscou-se, por meio desse estudo, avaliar as ações do planejamento do SGA, bem como a implantação da política ambiental, por intermédio de um modelo de auditória ambiental estruturado nas especificações e recomendações da ISO 19011 e ISO 14001 que viabilizam a identificação de pontos fortes e fracos no SGA.

\subsection{Descrição do Modelo de Auditoria}

O modelo de auditoria ambiental proposto nesse trabalho está estruturado nas especificações e recomendações da ISO 19011 que trata de diretrizes para auditorias de sistemas de gestão da qualidade e ambiental.

Ele possibilitará que a empresa obtenha o conhecimento da forma como suas atividades da gestão ambiental são desenvolvidas, oferecendo condições para um desempenho adequado dos requisitos legais e outros, proporcionando análise, apreciações, recomendações e comentários objetivos e/ou convenientes acerca das atividades investigadas.

O formato do modelo compõe-se de três fases, como mostra a Figura 2, sendo elas: planejamento, aplicação e conclusão da auditoria.

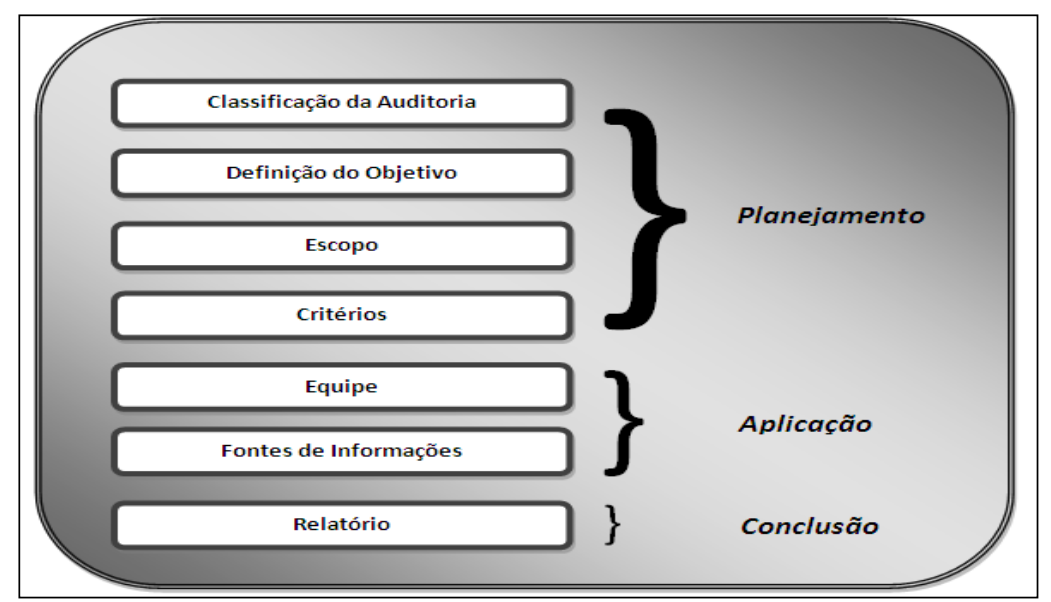

Figura 2 - Proposição do modelo de auditoria.

Fonte: Elaborado pelos autores. 
O planejamento da auditoria compõe as subfases de classificação, definição do objetivo, escopo e critérios da auditoria. A classificação permite identificar se a auditoria é de primeira, segunda ou terceira parte. O objetivo define o que é para ser realizado pela auditoria, o escopo descreve a abrangência e os limites da auditoria, tais como localizações físicas, unidades organizacionais, atividades e processos a serem auditados, e, os critérios definem os requisitos que serão auditados no sistema de gestão da empresa, objeto de estudo.

A aplicação do modelo de auditoria compõe as subfases, a definição da equipe e as fontes de informações da auditoria. A equipe deverá ser formada considerando as competências para atendimento dos objetivos da auditoria, podendo ser formada por um único indivíduo que execute todas as competências aplicáveis a um líder de equipe de auditoria, sendo elas atributos pessoais, conhecimento e habilidades genéricas e específicas, educação, experiência profissional, treinamento e experiência em auditoria, desenvolvimento profissional contínuo, entre outras.

A coleta de informações, visando à identificação de conformidade da política e do planejamento do sistema de gestão com a norma ISO 14001, utilizou como instrumento de coleta um check-list contendo os requisitos a serem averiguados, tais como o resultado do levantamento e um campo para relato de evidências, conforme Quadro 1.

Os requisitos a serem avaliados, ou seja, os critérios de auditoria (itens 4.2 e 4.3 da ISO 14001) foram extraídos da norma, de acordo com o processo de interpretação e classificação quanto o nível de comprometimento para o sistema. A busca de evidências de conformidade desses requisitos foi efetuada com base no levantamento e na análise de documentos e registros, entrevistas com responsáveis, além de observações in loco. Como resultado, o modelo apresenta três possibilidades: conforme $(\mathrm{C})$, quando foi evidenciado o atendimento dos requisitos da norma; não conformidade MENOR $(\mathrm{NC} \downarrow)$, quando não foi possível evidenciar a conformidade do sistema na sua totalidade, necessitando observar ainda alguns elementos ou quando a não conformidade não compromete o sistema e demais componentes; e não conformidade MAIOR (NC $\uparrow$ ), quando a não conformidade compromete o sistema e demais componentes.

\begin{tabular}{|c|c|r|r|r|l|}
\hline \multicolumn{2}{|c|}{ Nome do Requisito da NBR ISO 14001 } & \multicolumn{2}{|c|}{ Resultado } & \multirow{2}{*}{ Evidências } \\
\cline { 3 - 5 } & $\mathbf{C} \downarrow$ & $\begin{array}{c}\mathbf{N} \\
\mathbf{C} \uparrow\end{array}$ & \\
\hline$N$ & (descrição dos requisitos da norma) & & & & (lista das evidências encontradas) \\
\hline$\Sigma$ & & & & \\
\hline
\end{tabular}

Quadro 1: Modelo de Check list de auditoria

Fonte: Dados da pesquisa.

Por fim, a terceira fase do modelo, conclusão da auditoria, compreende o tratamento de dados, análise crítica das informações obtidas e elaboração do relatório final da auditoria com todos os dados obtidos e as recomendações necessárias.

\section{RESULTADOS E DISCUSSÕES}

O modelo em tela trata-se de uma auditoria de primeira parte, tendo como escopo a unidade fabril localizada no Estado do Rio Grande do Norte (RN) e critérios da auditoria os itens 4.2 Política Ambiental e 4.3 Planejamento da ISO 14001. A auditoria ambiental na empresa, objeto de estudo, foi realizada com o intuito de identificar as oportunidades de melhoria no Sistema de Gestão Ambiental.

\subsection{Aplicação do modelo}

De acordo com a norma ISO 14004, a fase de planejamento no Sistema de Gestão Ambiental é importante na formulação de um plano que oriente o cumprimento da política 
ambiental para assim, identificar, implementar e manter procedimentos para os aspectos ambientais, requisitos legais e objetivos, metas e programas da organização.

\subsubsection{Requisitos auditáveis}

Os pontos auditados pelo modelo foram: política ambiental; aspectos ambientais; requisitos legais; e objetivos metas e programas.

\section{a) Política ambiental}

A política ambiental consiste na orientação geral para o sistema de gestão ambiental, sendo importante por sistematizar os objetivos e metas da responsabilidade ambiental da empresas.

A empresa auditada possui um Sistema de Gestão Integrado que contempla a gestão da

qualidade, gestão ambiental e de segurança e saúde ocupacional. Sobre isso, a ISO 14001 não requer a implantação de um sistema de gestão isolado, possibilitando as organizações balizarem um sistema integrado. Assim, Política de Gestão Integrada trata da unificação de três políticas distintas em um único manual de Sistema de Gestão.

A auditoria do requisito 4.2 Política Ambiental da ISO 14001, evidenciou conformidade com a política da empresa. O Quadro 2 lista os requisitos, as evidências identificadas e a avaliação do atendimento.

\begin{tabular}{|c|c|c|c|c|}
\hline \multirow{2}{*}{\multicolumn{2}{|c|}{ Nome do Requisito: 4.2 Política ambiental }} & \multicolumn{2}{|c|}{ Resultado } & \multirow[b]{2}{*}{ Evidências } \\
\hline & & $\mathbf{N}$ & $\mathbf{N}$ & \\
\hline 1 & $\begin{array}{l}\text { A empresa tem sua política ambiental } \\
\text { documentada, aprovada e mantida pela alta } \\
\text { administração? }\end{array}$ & & & $\begin{array}{l}\text { Manual do Sistema de Gestão } \\
\text { integrada com aprovação pela alta } \\
\text { administração e divulgada em } \\
\text { outros meios. }\end{array}$ \\
\hline 2 & $\begin{array}{l}\mathrm{O} \text { escopo da política ambiental é apropriado às } \\
\text { atividades, produtos e/ou serviços da empresa? }\end{array}$ & & & $\begin{array}{l}\text { Manual do Sistema de Gestão } \\
\text { define o escopo, sendo todo o } \\
\text { Grupo empresarial. }\end{array}$ \\
\hline 3 & $\begin{array}{l}\text { Está incluso o comprometimento com a } \\
\text { melhoria continua e prevenção contra } \\
\text { poluição. }\end{array}$ & & & $\begin{array}{l}\text { Autodeclaração da política no } 4^{\circ} \mathrm{e} \\
5^{\circ} \text { objetivo. }\end{array}$ \\
\hline 4 & $\begin{array}{l}\text { Compromete-se em atender os requisitos } \\
\text { legais aplicáveis e outros subscritos pela } \\
\text { organização? }\end{array}$ & & & $\begin{array}{l}\text { Autodeclaração da política no } 2^{\circ} \\
\text { objetivo. }\end{array}$ \\
\hline 5 & $\begin{array}{l}\text { Orienta para o estabelecimento de objetivos e } \\
\text { metas? }\end{array}$ & & & Autodeclaração \\
\hline 6 & $\begin{array}{l}\text { Está comunicada a todos que trabalham na } \\
\text { empresa ou que atuem em seu nome? }\end{array}$ & & & $\begin{array}{l}\text { Crachá, lista de presença da } \\
\text { Semana do Sistema de Gestão } \\
\text { Integrada. }\end{array}$ \\
\hline 7 & Está disponível para o público? & & & Home page da empresa. \\
\hline & & $\mathbf{0}$ & & \\
\hline
\end{tabular}

Legenda: (C) Conformidade - (O) Necessita de observação - (N) Não conforme.

Quadro 2 - Auditoria dos requisitos NBR ISO 14001 item 4.2 Política ambiental.

Fonte: Dados da pesquisa

A empresa mantém uma política documentada, mantida e aprovada pela alta administração por meio do manual do Sistema de Gestão Integrada. Nele é declarado o escopo do SGA que compreende todo o grupo que compõe a empresa, atendendo o requisito da norma. A autodeclaração da política evidencia a conformidade com o comprometimento em relação a melhoria contínua, prevenção contra poluição e com o atendimento aos requisitos legais e outros subscritos pela organização, como também estabelece os objetivos e metas.

A comunicação interna da política é realizada por meio da incorporação do texto ao crachá de identificação dos funcionários e na Intranet. Além disso, é comunicada por meio de treinamento 
realizado anualmente cujo objetivo é sensibilizar os funcionários diretos e indiretos sobre a importância da Política do Sistema de Gestão da empresa. A comunicação externa ocorre por meio da Home page que demonstra ao público externo e as partes interessadas o seu compromisso ambiental e outros que a empresa possui, o que proporciona abertura para novos mercados, como aponta Reis e Queiroz (2002).

\section{b) Aspectos ambientais}

É por meio do levantamento dos aspectos e impactos ambientais significativos que os objetivos, metas e programas, além das rotinas organizacionais e operacionais para o gerenciamento dos aspectos ambientais significativos, são delineados, sendo, portanto, um importante passo para a consolidação da gestão ambiental na organização. Esse processo no Sistema de Gestão Ambiental está inserido na fase de planejamento, conforme especificações da NBR ISO 14001.

No que tange os aspectos ambientais, o texto da NBR ISO 14001:2004 destaca que a organização deve assegurar que os aspectos ambientais significativos sejam levados em consideração no estabelecimento, implementação e manutenção de Sistema de Gestão Ambiental. O Quadro 3 traz o check list correspondendo à auditoria relativa aos requisitos do item 4.3.1 Aspectos Ambientais da NBR ISO 14001. Assim, foi evidenciado que a empresa possui procedimento para identificar os aspectos e impactos ambientais das suas atividades, produtos e serviços. A organização, de acordo com a norma deverá assegurar que este procedimento seja implementado e mantido, este poderá ser evidenciado por uma planilha de avaliação do levantamento dos aspectos e impactos ambientais significativos e o registro de atualizações.

\begin{tabular}{|c|c|c|c|}
\hline \multirow[b]{2}{*}{ 4.3.1 Aspectos Ambientais } & \multicolumn{2}{|c|}{ Resultado } & \multirow[b]{2}{*}{ Evidências } \\
\hline & $\mathbf{C} \mathbf{C}_{\downarrow}^{\mathbf{N}}$ & $\begin{array}{c}\mathbf{N} \\
\mathbf{C} \uparrow\end{array}$ & \\
\hline $\begin{array}{l}\text { A organização tem procedimentos para } \\
\text { identificar os aspectos e impactos ambientais das } \\
\text { suas atividades, produtos e serviços? }\end{array}$ & & & $\begin{array}{l}\text { Documento: Levantamento de } \\
\text { Aspectos/Perigos e Impactos / Danos. }\end{array}$ \\
\hline $\begin{array}{l}\text { Caso afirmativo no item } 1 \text {, os procedimentos } \\
\text { estão estabelecidos, implementados e mantidos? }\end{array}$ & & $\mathbf{X}$ & $\begin{array}{l}\text { Não há registros do levantamento dos } \\
\text { aspectos e impactos ambientais } \\
\text { significativos, porém, sua realização } \\
\text { está prevista no Plano de ação. }\end{array}$ \\
\hline $\begin{array}{l}\text { O procedimento de levantamento de aspectos } \\
\text { ambientais atende ao escopo do SGA? }\end{array}$ & & $\mathbf{X}$ & $\begin{array}{l}\text { Item } 2.0 \text { do procedimento Levantamento } \\
\text { de Aspectos/Perigos e Impactos / Danos } \\
\text { define escopo. } \\
\text { Não há registros da aplicação do } \\
\text { procedimento. }\end{array}$ \\
\hline $\begin{array}{l}\text { O procedimento leva em consideração a criação } \\
\text { de novos produtos, atividades ou serviços, ou até } \\
\text { mesmo, a modificação dos já existentes? }\end{array}$ & & & $\begin{array}{l}\text { Item } 6.0 \text { do procedimento Levantamento } \\
\text { de Aspectos/Perigos e Impactos / } \\
\text { Danos. }\end{array}$ \\
\hline $\begin{array}{l}\text { O procedimento é claro na definição de critérios } \\
\text { para determinar se os aspectos tenham ou } \\
\text { possam ter impactos significativos sobre o meio } \\
\text { ambiente? }\end{array}$ & & & $\begin{array}{l}\text { Procedimento classifica os aspectos: } \\
\text { Nível de importância } \geq 6 \text { e/ou } \\
\text { Gravidade Alta }=3 \text {. }\end{array}$ \\
\hline $\begin{array}{l}\text { A planilha de levantamento de aspectos e } \\
\text { impactos ambientais está atualizada? }\end{array}$ & & $\mathbf{X}$ & Não há registros. \\
\hline $\begin{array}{l}\text { Os aspectos e impactos ambientais significativos } \\
\text { da empresa estão identificados conforme o } \\
\text { procedimento? }\end{array}$ & & $\mathbf{X}$ & Não há registros. \\
\hline$\sum$ & $\mathbf{0}$ & 4 & - \\
\hline
\end{tabular}

Legenda: (C) Conformidade - (O) Necessita de observação - (N) Não Conforme

Quadro 3 - Auditoria dos Requisitos NBR ISO 14001 item 4.3.1 Aspectos Ambientais

Fonte: Dados da pesquisa. 
A auditoria não evidenciou a implementação de procedimento e registros contendo a avaliação dos aspectos e impactos. Assim, observa-se que mesmo obtendo um procedimento contendo instruções de como identificar, avaliar e priorizar os aspectos ambientais, ele não foi implementado. Este é o principal motivo do enquadramento como uma não conformidade MAIOR, já que todo o sistema depende da definição dos aspectos ambientais significativos.

Alguns outros requisitos considerados na auditoria foram: se o procedimento atende ao escopo do SGA; se considera a criação de novos produtos, atividades ou serviços, ou até mesmo, a modificação dos já existentes; e se há critérios para determinar os aspectos e impactos ambientais significativos. Em todos esses pontos houve conformidade, de acordo com as evidências apresentadas no Quadro 3, exceto quanto ao atendimento do escopo, pois, não há evidencias de registros da aplicação do procedimento na unidade fabril de Macaíba/RN.

Quanto à criação de novos produtos, atividades e serviços o procedimento considera que as planilhas devem ser revisadas ou reavaliadas, quando houver alterações das condições nas quais os aspectos/perigos e seus impactos/danos forem avaliados.

Os aspectos/perigos e seus impactos/danos são avaliados quando há alterações em gravidade e probabilidade, novos aspectos/ perigos, exclusão de aspectos/ perigos existentes, novos produtos, novos processos, inclusão e/ou exclusão de áreas, alteração dos controles operacionais, entre outros.

Quanto aos critérios de significância para aspectos e impactos ambientais o procedimento classifica quando possuírem nível de importância maior ou igual a seis e/ou gravidade alta, conforme metodologia do procedimento.

\section{c) Requisitos legais}

Para atender os requisitos legais aplicados às suas atividades, a organização precisa desenvolver mecanismos de identificação e criar instrumentos para que todos os envolvidos tenham compreensão deles. Além disso, os requisitos legais devem levar em consideração os aspectos e impactos ambientais identificados pela empresa, possuindo procedimentos estabelecidos, implementados e mantidos em seu sistema de gestão ambiental.

Conforme evidências da auditoria do requisito 4.3.1 Aspectos Ambientais, a empresa não apresentou registros contendo a avaliação dos aspectos e impactos ambientais, considerada fundamental para o atendimento aos requisitos legais aplicáveis. Apesar da empresa não ter aplicado esse procedimento, ela vem considerando os mesmos aspectos e impactos ambientais identificados na avaliação da matriz, repassados por meio de uma listagem. No entanto, essa listagem não garante que os mesmos aspectos da matriz sejam todos vislumbrados na filial, podendo haver algumas particularidades. Dessa forma, evidencia-se uma não conformidade MENOR do sistema, uma vez que não há uma garantia que todos os requisitos legais estejam sendo levantados (Item 3, Quadro 4).

Diante disso e da inserção da avaliação dos aspectos e impactos ambientais no Plano de Ação Corretivo da empresa, para a auditoria do requisito 4.3.2 Requisitos Legais e Outros, este não atendimento não foi interpretado como uma não conformidade. Desse modo, a auditoria foi direcionada aos demais requisitos do item 4.3.2, como mostra o Quadro 4.

\begin{tabular}{|l|l|l|l|l|}
\hline \multicolumn{2}{|c|}{ 4.3.2 Requisitos legais e outros } & \multicolumn{2}{|c|}{ Resultado } & \multicolumn{1}{|c|}{ Evidências } \\
\cline { 2 - 4 } & & $\begin{array}{c}\mathbf{N} \\
\mathbf{C} \downarrow\end{array}$ & $\mathbf{C} \uparrow$ & \\
\hline & $\begin{array}{l}\text { A organização tem procedimentos para } \\
\text { identificar e ter acesso aos requisitos legais } \\
\text { relacionados aos seus aspectos ambientais? }\end{array}$ & & $\begin{array}{l}\text { Documento Avaliação e Atendimento de } \\
\text { Legislações. } \\
\text { Software SISLEG NET }\end{array}$ \\
\hline $\begin{array}{l}\text { Caso afirmativo no item 1, os procedimentos } \\
\text { estão estabelecidos, implementados e mantidos? }\end{array}$ & & $\begin{array}{l}\text { Aprovação, da alta administração, Lista de } \\
\text { presença de treinamento do SISLEG, } \\
\text { Relatórios do SISLEG. }\end{array}$ \\
\hline
\end{tabular}

Revista de Gestão Social e Ambiental - RGSA, São Paulo, v. 5, n. 1, p. 66-84, jan./abr., 2011. 


\begin{tabular}{|l|l|r|r|l|}
\hline $\begin{array}{l}\text { A organização identificou todos os requisitos } \\
\text { legais aplicáveis e outros }\end{array}$ & $\mathbf{X}$ & & $\begin{array}{l}\text { Não há registros de todos os aspectos } \\
\text { ambientais da organização, logo não há } \\
\text { garantia que todos os requisitos tenham } \\
\text { sido levantados. }\end{array}$ \\
\hline $\begin{array}{l}\text { O procedimento determina como os requisitos } \\
\text { se aplicam aos seus aspectos ambientais? }\end{array}$ & $\mathbf{X}$ & $\begin{array}{l}\text { Documento Avaliação e Atendimento de } \\
\text { Legislações }\end{array}$ \\
\hline $\begin{array}{l}\text { Há registros que asseguram que a organização } \\
\text { leva em consideração os requisitos legais no } \\
\text { estabelecimento, implementação e manutenção } \\
\text { do seu gerenciamento ambiental? }\end{array}$ & $\begin{array}{l}\text { Observar se a empresa identificou e leva } \\
\text { em consideração os padrões estabelecidos } \\
\text { pela legislação nos procedimentos } \\
\text { operacionais - emissões atmosféricas, } \\
\text { efluentes e resíduos sólidos, etc. }\end{array}$ \\
\hline$\sum$ & $\mathbf{0}$ & - \\
\hline
\end{tabular}

Legenda: (C) Conformidade - (O) Necessita de observação - (N) Não conforme

Quadro 4- Auditoria dos requisitos NBR ISO 14001 item 4.3.2 Requisitos Legais e Outros

Fonte: dados da pesquisa.

Assim, foi evidenciado o procedimento Avaliação e Atendimento de Legislações, que tem por objetivo garantir o atendimento dos requisitos legais aplicados aos negócios da empresa. Esse procedimento aborda como deve ser realizada a identificação dos requisitos legais aplicados, quem são os responsáveis, como avaliar a aplicabilidade, a atualização e o monitoramento das normas e leis, assim como o treinamento dos gestores sobre como gerenciar o atendimento das legislações.

O procedimento define o programa SISLEG NET como o instrumento para realizar a identificação dos requisitos legais, trata-se, portanto, de um software contendo uma coletânea de legislações federais, estaduais e municipais sobre meio ambiente, normas técnicas, entre outros requisitos ligados às atividades de negócio da empresa.

O software realiza mensalmente a atualização da legislação nas três esferas - Federal, Estadual e Municipal, assim como do surgimento de novas regulamentações. Fica sobre a responsabilidade dos gestores de cada área da empresa, acompanhar tal atualização, realizar auditorias internas e manter os registros atualizados.

Cabe ressaltar, que além de fornecer listas de verificação, o programa em seus relatórios indica as ações necessárias para o cumprimento de não conformidades, estabelece prazo para atendimento aos requisitos, notifica os pendentes, concluídos e programados, fornece relatórios das atividades e relatórios estatísticos.

Quanto ao requisito 4 do Quadro 4, foi evidenciado o procedimento Avaliação e Atendimento de Legislações que responsabiliza o gestor de meio ambiente e o setor jurídico da empresa para avaliar e entender a aplicabilidade das legislações ambientais em relação aos aspectos e impactos ambientais decorrentes da atividade da organização, atendendo assim ao requisito.

O estabelecimento, a implementação e manutenção do procedimento foi evidenciado mediante a aprovação do documento pela alta administração da organização, lista de presença de treinamentos e relatórios do software de gestão dos requisitos legais (SISLEG NET).

Por fim, a NBR ISO 14001:2004 exige que a organização assegure que os requisitos legais sejam levados em consideração no estabelecimento, implementação e manutenção do seu gerenciamento ambiental. Esse requisito foi avaliado como necessita de observação (O), pois é necessário verificar se a empresa identificou e leva em consideração os padrões estabelecidos pela legislação. Esse requisito é avaliado por meio do item 4.5 Verificação.

\section{d) Objetivos, metas e programas}

As organizações, de acordo com a NBR ISO 14001:2004, devem ter programas, objetivos e metas ambientais documentados nas funções e nos níveis relevantes. $\mathrm{O}$ atendimento desse requisito na auditoria em estudo foi avaliado como uma não conformidade MENOR, como mostra o Quadro 5. Apesar da empresa manter os programas documentados, alguns não estão devidamente implementados e sem metas claramente definidas. 


\begin{tabular}{|c|c|c|c|}
\hline \multirow[b]{2}{*}{ 4.3.3 Objetivos, Metas e Programa(s) } & \multicolumn{2}{|c|}{ Resultado } & \multirow[b]{2}{*}{ Evidências } \\
\hline & $\mathbf{C}_{\downarrow}^{\mathbf{N}}$ & $\begin{array}{c}\mathbf{N} \\
\mathbf{C} \uparrow\end{array}$ & \\
\hline $\begin{array}{l}\text { A organização tem estabelecido, implementado e } \\
\text { mantido programas, objetivos e metas ambientais } \\
\text { documentados, nas funções e níveis relevantes na } \\
\text { organização? }\end{array}$ & $\mathbf{X}$ & & $\begin{array}{l}\text { Documentados no Sistema de Gestão } \\
\text { Integrada; Lista de presença do programa } \\
\text { de integração; Objetivos e metas } \\
\text { ambientais ainda não implementados. }\end{array}$ \\
\hline $\begin{array}{l}\text { Os objetivos e metas são mensuráveis (quando } \\
\text { possível) e coerentes com a política ambiental, } \\
\text { consideram os requisitos legais e outros } \\
\text { requisitos subscritos e a melhoria continua? }\end{array}$ & $\mathbf{X}$ & & $\begin{array}{l}\text { Carta do gerente regional não mensurou } \\
\text { todas as metas para unidade fabril de } \\
\text { Macaíba no ano de } 2008 \text {; }\end{array}$ \\
\hline $\begin{array}{l}\text { A organização considera os } r \text { aspectos } \\
\text { operacionais (opções tecnológicas, requisitos } \\
\text { financeiros, operacionais, comerciais e a visão } \\
\text { das partes interessadas)? }\end{array}$ & $\mathbf{X}$ & & $\begin{array}{l}\text { Procedimentos coorporativos; } \\
\text { Relatórios e atas de reuniões. }\end{array}$ \\
\hline $\begin{array}{l}\text { Os programas contemplam responsáveis, meios e } \\
\text { prazos para atendimento dos objetivos e metas? }\end{array}$ & $\mathbf{X}$ & & Programas ainda não implementados. \\
\hline$\sum$ & 4 & 0 & - \\
\hline
\end{tabular}

Legenda: (C) Conformidade - (O) Necessita de observação - (N) Não conforme

Quadro 5 - Auditoria dos requisitos NBR ISO 14001 item 4.3.3 Objetivos, Metas e Programas

Fonte: Dados da pesquisa.

Quanto à mensuração e coerência dos objetivos e metas ambientais com a política ambiental, a empresa deve ter definido o propósito ambiental geral, o requisito de desempenho detalhado e os prazos para o alcance das metas. No entanto, foi evidenciada, por meio das análises documentais do manual do sistema de gestão integrada, requisitos coorporativos e carta enviada pelo gerente regional à empresa, a ausência de metas mensuráveis em alguns dos seus objetivos, classificando o atendimento desse requisito como necessita de observação.

$\mathrm{O}$ fato de a empresa ter iniciado suas atividades no segundo semestre de 2007 levaram os gestores a decidir pelo estabelecimento das metas ambientais a partir de 2009, justificando a inexistência de um histórico em que pudessem determinar metas coerentes com a realidade da organização.

Na Tabela 1 são listados objetivos e metas ambientais da organização. Cabe ressaltar que a empresa, objeto de estudo, é franqueada e que algumas das suas metas são delineadas pela matriz, tais como a quantidade de PET comercializada que é coletada para reciclagem, os limites de lançamento de efluentes e a conformidade com os requisitos legais. Os demais objetivos listados serão definidos pela empresa após o estudo de um histórico de três semestres de funcionamento.

Tabela 1 - Objetivos e metas ambientais da franquia

\begin{tabular}{|c|c|}
\hline Objetivos ambientais & Metas \\
\hline Redução do consumo de água & - \\
Redução do consumo de energia & - \\
Redução de resíduos sólidos & - \\
Îndice de reciclagem & $5 \%$ do total comercializado \\
Coleta de PET comercializada & $>90 \%$ dos limites de lançamento \\
Tratamento de efluentes & $100 \%$ \\
Conformidade com os requisitos legais & \\
\hline
\end{tabular}

$$
\text { Fonte: Dados da pesquisa. }
$$

Mensalmente a empresa acompanha o desempenho ambiental monitorando todos os aspectos dos programas de gestão ambiental - requisitos legais, reciclagem e minimização de resíduos sólidos, consumo de água e energia, tratamento de efluentes, emissão atmosférica de gases 
e requisitos financeiros da reciclagem dos resíduos sólidos - por meio de um instrumento chamado rating ambiental.

Quanto ao estabelecimento, implementação e manutenção dos programas ambientais, seguem sistematizados com o respectivo diagnóstico evidenciado pela auditoria:

a) Equipe de ecoeficiência de água - Trata-se de uma equipe formada por colaboradores internos, responsáveis pelo objetivo de redução do consumo de água na empresa. Não foram evidenciados registros de um programa ambiental para redução de água, aprovado pela alta administração, que seja estabelecido, implementado e documentado. Algumas práticas evidenciadas para a redução do consumo de água foram: água utilizada na assepsia de embalagens que retorna para Estação de Tratamento, sendo reutilizada no processo de fabricação do produto e na utilização do efluente tratado na irrigação do gramado e jardins da empresa, porém não há nenhum monitoramento da realização e eficácia dessas atividades;

b) Equipe de ecoeficiência de energia - Trata-se de uma equipe formada por colaboradores internos, responsáveis pela redução do consumo de energia elétrica na empresa. Não foram evidenciados registros de um programa ambiental para redução de energia, aprovado pela alta administração, que esteja estabelecido, implementado e documentado, assim como não há registros de ações realizadas pela equipe nos últimos meses;

c) Dia Mundial de Limpeza de Praias - Programa estabelecido pela empresa matriz, onde a franquiada atua anualmente na limpeza das praias por meio da coleta de lixo e ações de educação ambiental junto à população. O programa está estabelecido, implementado e documentado, porém não foi evidenciada a mensuração de metas;

d) Programa de Reciclagem - Trata-se de um programa realizado na comunidade externa, que tem como objetivo coletar embalagens dos produtos comercializados pela empresa como PETs e latas de alumínio. O programa está estabelecido, implementado e documentado, e, há a clareza na mensuração das metas e dos prazos estabelecidos. A partir de 2007, ano do início de funcionamento da empresa, a matriz estabeleceu metas de coleta de PET para reciclagem, conforme mostrado na Tabela 2.

Tabela 2 - Meta para coleta de PET em relação ao total comercializado

\begin{tabular}{c|c}
\hline Ano & $\begin{array}{c}\text { Meta para coleta de } \\
\text { PET comercializado (\%) }\end{array}$ \\
\hline 2007 & $3 \%$ \\
2008 & $5 \%$ \\
2009 & $7 \%$ \\
2010 & $10 \%$ \\
\hline
\end{tabular}

Fonte: Pesquisa de campo, 2008.

A empresa assegura a manutenção dos objetivos, metas e programas da empresa por meio de um comitê composto por diretores e gerentes corporativos que analisam e os atualizam mensalmente no Plano de Gestão Integrada.

Quanto ao item 3 do Quadro 5, a organização deve considerar seus aspectos operacionais ao estabelecer seus objetivos e metas. Portanto, nesse aspecto, foi evidenciado conformidade no texto do Programa de Gestão Ambiental da Norsa, notando o comprometimento ao considerar os aspectos operacionais na definição de seus objetivos e metas, como também na elaboração de programas e instruções operacionais de trabalho. Foi evidenciado ainda, atas de reuniões com fornecedores, onde havia o estudo e negociação da aplicação das melhores tecnologias que se adéquam as operações da empresa e que sejam viáveis economicamente.

Por último, o Manual do Sistema de Gestão Integrado e outros documentos coorporativos foram auditados, em razão do estabelecimento de responsáveis, meios e prazos dos programas ambientais da empresa. Essa definição é indispensável para que o atendimento dos objetivos e das 
metas ambientais sejam efetivados. Assim, esse requisito foi considerado como uma nãoconformidade MENOR mediante a evidência de que alguns dos programas não têm responsáveis deliberados e documentados e ainda por possuir algumas das metas ambientais em status de definição.

Portanto, de maneira geral, em relação aos requisitos da ISO 14001 do item 4.3.3 Objetivos, Metas e Programa(s), foram evidenciados conformidades e não conformidades, porém as não conformidades foram classificadas como necessita de observação, em razão da empresa estar ciente dos requisitos e está planejando a mensuração de suas metas ambientais.

\subsubsection{Conclusão da auditoria}

Nesse item são apresentados os pontos fortes e as oportunidades de melhoria evidenciados na auditoria, assim como a validação do modelo de auditoria ambiental proposto nesse estudo.

\section{a) Pontos fortes evidenciados na auditoria}

Quanto à política da empresa, os pontos fortes evidenciados foram os seguintes: política documentada, implementada e mantida por meio do Sistema de Gestão Integrada; comprometida com a melhoria contínua, prevenção da poluição, requisitos legais e demais requisitos da ISO 14001; boa comunicação interna e externa.

Quanto aos aspectos ambientais, os pontos fortes evidenciados foram os seguintes: existência de procedimento interno para levantamento dos aspectos e impactos ambientais significativos, com critérios técnicos satisfatórios, por exemplo, o fato do procedimento levar em consideração a criação de novos produtos, atividades, serviços ou a modificação dos já existentes, além da clareza na definição dos aspectos e impactos ambientais significativos.

Quanto aos requisitos legais, os pontos fortes evidenciados foram os seguintes: existência de procedimento de identificação e acesso aos requisitos legais estabelecidos, implementados e mantidos pela empresa; o procedimento responsabiliza pessoas competentes para determinar a aplicação dos requisitos legais aos aspectos ambientais da empresa; a empresa possui um software que auxilia no gerenciamento dos requisitos legais.

Quanto aos objetivos, metas e programas ambientais os pontos fortes evidenciados foram os seguintes: objetivos, metas e programas coerentes com o escopo do SGA da organização; objetivos, metas e programas ambientais documentados e aprovados pela alta administração.

\section{b) Oportunidades de melhoria evidenciadas na auditoria}

Quanto aos aspectos ambientais, recomenda-se as seguintes oportunidades de melhoria: implementar o procedimento de levantamento dos aspectos e impactos ambientais significativos; assim como manter os aspectos e impactos significativos determinados de forma que sejam levados em consideração no estabelecimento, implementação e manutenção do Sistema de Gestão Ambiental.

Quanto aos requisitos legais, recomenda-se a seguinte oportunidade de melhoria: averiguar se a listagem de aspectos ambientais da filial é igual ao da Mariz e, caso necessário, efetuar um novo levantamento de requisitos legais e outros.

Quanto aos objetivos, metas e programas ambientais, recomendam-se as seguintes oportunidades de melhoria: estabelecimento e implementação de metas e programas para os seguintes objetivos ambientais: redução do consumo de água, de energia, da geração de resíduos sólidos, índice de reciclagem; consolidar a equipe de ecoeficiência de energia elétrica; criar um programa de educação ambiental documentado e aprovado pela alta administração, servindo como um instrumento facilitador para a melhoria contínua dos objetivos, metas e programas ambientais, em conformidade com o item 4.4.2 da norma ISO 14001; além do programa interno de reciclagem, recomenda-se também criar uma equipe de ecoeficiência de resíduos sólidos, buscando promover 
uma redução da geração, reutilização e a reciclagem dos resíduos na empresa; no programa Dia Mundial de Limpeza de Praias recomenda-se estabelecer metas como número de funcionários participantes e quantidade de resíduos coletados; transformar as equipes de ecoeficiência de água e energia em dois programas ambientais documentados, implementados e aprovados pela alta administração em Programa de Eficiência da Água e Programa de Eficiência Energética; transformar as instruções de trabalho "Coleta Seletiva" e "Gerenciamento de Resíduos Sólidos" em um Programa de Gestão de Resíduos Sólidos, integrando as informações de forma a tornar a gestão de resíduos mais eficiente.

\section{2 Validação do modelo de auditoria ambiental}

A validação do modelo da auditoria ambiental se deu a partir dos resultados obtidos com a sua aplicação e a aplicabilidade a outros segmentos. Foram consideradas limitações do modelo a aplicabilidade em auditar a política ambiental e a fase de planejamento do Sistema de Gestão Ambiental, da empresa em estudo além da possibilidade de omissão de informações pelo auditado, que diminui a confiabilidade da auditoria. Porém, esse escopo foi justificado pelo nível de maturidade da implantação do SGA.

De forma geral, o modelo permitiu uma análise prática e crítica da situação real do SGA da empresa, possibilitando a identificação de pontos conformes e as não conformidades - Menor e Maior. Diante disso, foi possível levantar pontos fortes e oportunidades de melhoria no SGA auditado.

Destaca-se ainda, que a padronização dos pontos a serem auditados em um check list dinamizou o processo de levantamento de evidências de conformidade, diminuindo o tempo de seu levantamento e dando solidez no processo. Em adição, esse processo de auditoria foi favorecido também pela clareza na busca das evidências, estabelecendo três possibilidades - análise de documentos e registros do SGA; entrevistas e observações in loco.

Assim, observa-se aplicabilidade desse modelo de auditorias de primeira ou segunda parte para as fases de política ambiental e planejamento do Sistema de Gestão Ambiental em diferentes tipos e portes de organizações.

\section{CONSIDERAÇÕES FINAIS}

Esse trabalho procurou avaliar o Sistema de Gestão Ambiental de uma empresa do ramo alimentício, localizada na microrregião de Natal/RN, partindo da proposição de um modelo de auditoria ambiental estruturada na ISO 19011 e a aplicação dos requisitos 4.2 Política Ambiental e 4.3 Planejamento de um SGA requerido pela ISO 14001.

Quanto à proposta de elaborar um modelo de auditoria, a sua aplicação foi satisfatória na análise de conformidade dos requisitos da NBR ISO 14001:2004, evidenciando pontos fortes e oportunidades de melhoria no Sistema de Gestão Ambiental da empresa. Destaca-se a facilidade da aplicação do modelo, assim como o dinamismo na coleta dos dados utilizados, permitindo uma visão ampla da organização e de forma rápida.

$\mathrm{Na}$ apresentação dos resultados da auditoria, a organização pode avaliar os seus aspectos positivos e negativos relacionados à gestão ambiental, facilitando a tomada de decisão. Portanto, percebe-se que ele pode ser aplicado em qualquer organização que deseje reconhecer oportunidades de melhoria em seu Sistema de Gestão Ambiental (auditoria de primeira parte) ou de outras organizações que desejem firmar parcerias comerciais (auditoria de segunda parte), em particular para a política ambiental e a fase de planejamento de um SGA.

Em linhas gerais, foi observado que a empresa está em conformidade quanto ao item 4.2 da ISO 14001, porém na fase de planejamento ambiental, foram identificadas algumas não conformidades, tanto menor quanto maior. De forma geral, foi observado um total de 13 conformidades, 6 não conformidade menor e 4 não conformidades maior. 
Apesar de existir um procedimento de avaliação, não foram evidenciados registros contendo os aspectos e impactos significativos. Sendo assim, não há confiabilidade no levantamento dos requisitos legais e outros aplicáveis a organização, no sentido em que não se sabe se todos os aspectos e impactos ambientais significativos vêm sendo levados em consideração no atendimento aos requisitos legais. A importância da definição dos aspectos e impactos ambientais significativos também é necessária para criar e estruturar os objetivos, metas e programas da empresa.

De maneira geral, conclui-se que o Sistema de Gestão Ambiental de qualquer organização pode ser estudado e aprimorado por meio da auditoria ambiental, ferramenta prática que propõe resultados que auxiliam na verificação do desempenho ambiental, identificando os pontos fortes e as oportunidades de melhoria na gestão, e, o alcance de um SGA eficiente que proporciona resultados econômicos e ambientais satisfatórios.

\section{REFERÊNCIAS}

ABNT - ASSOCIAÇÃO BRASILEIRA DE NORMAS TÉCNICAS. NBR ISO 19011: diretrizes para auditorias de sistema de gestão da qualidade e/ou ambiental. Rio de Janeiro: ABNT, 2002.

. NBR ISO 14001: sistema de gestão ambiental: especificação e diretrizes para o uso. Rio de Janeiro: ABNT, 2004.

NBR ISO 14001: sistema de gestão ambiental: requisitos com orientação ao uso. Rio de Janeiro: ABNT, 1996.

. NBR ISO 14004: sistema de gestão ambiental: diretrizes gerais sobre princípios, sistemas e técnicas de apoio. Rio de Janeiro: ABNT, 1996.

Attie, W. Auditoria: conceitos e aplicações. São Paulo: Atlas, 1998.

Barbieri, J. C. (2004). Gestão ambiental empresarial: conceitos, modelos e instrumento. São Paulo: Saraiva.

Cantarino, A. A. A. (2009) A importância da auditoria ambiental a gestão empresarial moderna. Recuperado em 28 jul. 2009 de http://www.niead.ufrj.br

Conceição Neto, A. A. da. (2001) Auditoria ambiental interna: uma ferramenta para a gestão empresarial. UFSC, Florianópolis.

D’isep, C. F. M. (2004) Direito ambiental econômico e a ISO 14000: análise jurídica do modelo de gestão ambiental e certificação ISO 14001. São Paulo: Revista dos Tribunais.

Fornasari Filho, N., Braga, T. O, Batistucci, S., G.G., Montanhesi, M. O. R (1994). Auditoria e sistema de gerenciamento ambiental (ISO 14.000). In: Simpósio Sulamericano, I e Simposio Nacional de Recuperação de Áreas Degradadas II, Foz do Iguaçu, 1994. Anais... Curitiba: FUPEF.

Glavic, P., Lukman, R. (February 2007). Review of sustainability terms and their definitions. Journal of Cleaner Production, (15), 1875-1885.

Moreira, M. S. Estratégias e implantação do sistema de gestão ambiental: modelo ISO 14000. Nova Lima: INDG, 2006. 
Pereira, M. A., Marques, C. S. A., Aguiar, E.M.( jan/mar, 2003) Sugestões para uma proposta do uso de novas ferramentas tecnológicas de informação para um sistema de gestão ambiental: ISO 14000. Engenharia Sanitária e Ambiental, 8 (1), 49-53.

Pimenta, H. C. D. Et Al. (2003) Manual de planejamento do sistema de gestão ambiental: um estudo de caso na agroindústria. In: Congresso Brasileiro de Engenharia Sanitária e Ambiental. Joinville. Anais... Joinville, 22.

Piva, A. L. (2007) Auditoria ambiental: um enfoque sobre a auditoria ambiental compulsória e a aplicação dos princípios ambientais. Paraná: Pontifícia Universidade Católica, 2007. Recuperado em 15 julho, 2008, de http://www.unifae.br/publicacoes/pdf/IIseminario /pdf_praticas/praticas_11.pdf

Reis, L.F.S.S.D., Queiroz, S.M.P. de (2002). Gestão ambiental em pequenas e médias empresas. Rio de Janeiro: Qualitymark.

Lei Complementar $n^{\circ}$ 272. (2009) Dispõe sobre a Política e o Sistema Estadual do Meio Ambiente, as infrações e sanções administrativas ambientais, as unidades estaduais de conservação da natureza, institui medidas compensatórias ambientais, e dá outras providências. Recuperado em: 10 jul. 2009, de http://www.gabinetecivil.rn.gov.br/acess/pdf/leicom272.pdf.

Silva, E.L.S. da, Menezes, E.M. (2001) Metodologia da pesquisa e elaboração de dissertação. Florianópolis: UFSC.

Silva, M. A. Assis, M. D. P. C. A. (2003) Auditoria Ambiental. Pernambuco: FACAPE.

Valle, C.E. (2000) Como se preparar para as normas ISO 14000: qualidade ambiental: o desafio de ser competitivo protegendo o meio ambiente. São Paulo: Pioneira.

Data do recebimento do artigo: 07/09/2009

Data do aceite de publicação: 24/03/2011

Revista de Gestão Social e Ambiental - RGSA, São Paulo, v. 5, n. 1, p. 66-84, jan./abr., 2011. 